\title{
Building Materials Lease Management System
}

\author{
Zhichu Lu
}

Information and Network Administrative Center, Jiangxi University of Technology, Nanchang 330029, Jiangxi, China

Keywords: Construction materials; Lease management; Automatic settlement; JAVA

\begin{abstract}
. in order to improve the scientific management level of building materials lease system; based on JAVA technology, and demand analysis on building materials leasing company; combined with the features of the business process of different companies, this paper designed a set of building material lease management system which is extensible and based on JAVA. The main function of the system is to realize the following functions between building materials leasing company and leaseholder: leasing contract, material dispatch, automatic storage of materials, material damage and automatic settlement; and realize the modernization management of building materials management for the building materials leasing company. The realized functions of construction material leasing management of this system greatly improved the management level of the enterprise.
\end{abstract}

\section{Summary}

The powerful computer science has covered many fields, which also plays a more and more important role in many aspects of construction. Building material lease management system is indispensable management means to building materials leasing company under the condition of modern information society. But for a long time, building material lease company mainly adopts office software to manage materials, which depends on manual work a large extent. There are many shortcomings, such as: low efficiency, errors, wastes of resources, etc. A large number of documents and data will be difficult to manage, find, update and maintenance for a long time.

At present, there are much professional software in the aspect of building supplies leasing industry, mainly for a specific business areas, such as contract management, in-out warehouse management, settlement, etc., but so far none software is developed for contract management, in-out warehouse and settlement management to get a comprehensive management.

According to the building materials leasing company management operation mode, to develop a system which can realize leasing contract management and equipment of in-out warehouse management for building materials leasing company management. And realize the implementation of various kinds of lease contract to add, modify, query, the enter registration of equipment, leasing funds settlement and complete material management of building materials leasing company.

\section{System analyses}

The feasibility analysis. Technical feasibility analysis

This system adopts the large database system Mysql, the client need to install dedicated client software to interact with the database data. Above is conventional equipment, which can be implemented under the existing conditions, so the system can run on all computers.

Economic feasibility analysis 
The scientific and standardized management and information features of timeliness, sharing, interactive makes developing a building lease management system is an inevitable trend. And the system is with low cost, high efficiency and useful to related functional departments, as well as the ability to invest.

Legal feasibility analysis

Because there is a contract in this system as the basis of cooperation, none infringement, obstruction and responsibility is existed. Even does, it also can be analyzed according to the contract as someone certainly will be responsible to. So the system can develop completely.

The analysis of system requirements. In building materials leasing business process, only after signing leasing contract can the leaseholder get building materials in the leasing company's warehouse. And the company management personnel will record the lease, in order to realize the modern management of building materials.

Landing system shows display interface, suggesting the company internal staff login system, and identity ID to set access permission.

After entering the landing interface is the main interface, which shows interfaces among function modules. Click on the corresponding link function can realize the corresponding function. The main interface includes: contract management, enter warehouse management, out warehouse management, damage management and settlement management, which is the five main function modules of system implementation.

Contract management includes draft a new contract, modify, query and delete contract under the appropriate authority.

Delivery management can be implemented by drafting a new out-stock order, modifying, querying and deleting the order in the corresponding permission.

Storage management can be implemented by drafting a new in- stock order, modifying, querying and deleting the order in the corresponding permission.

Damage management can be implemented by recording the damaged goods and saved into the database reserved for settlement.

Settlement management can be implemented by automatic settlement.

Software function process analysis. Considering the cost of the system, the system adopts the open source software and framework to build. The costs of open source software are relatively low, and the function is simple.

Development tools and supporting environment: the development of the system adopts MyEclipse. Considering scalability of the system and the independence of the entity class, Spring is used as the server-side container to realize the implementation of J2EE. Ibatis components are used to access database. The adoption of the open source software reduces the difficulty of system development and improves the reusability of the software.

Landing interface after starting the software; get into the main interface, to realize the function of different modules through the main link. Building materials leasing company first create the lease contract; record the basic information of the leaseholder, and create delivery and storage order. Delivery and storage order include multiple outbound and inventory items respectively, which realize the management of construction materials; improve the company's management efficiency and reduce the consumption of the labor force. 


\section{Database design}

The content of the database design includes two aspects:

Database logic design: design of the database logic structure, has nothing to do with specific DBMS, mainly reflect the business logic.

Database physical design: design the physical structure of the database; select RDBMS (e.g., Oracle, Mysql, etc.) according to the logic of the database structure, and design and implement storage structure and access mode of the database, etc.

Needs analysis of database. The main task of needs analysis is through detailed investigation of the target objects, including an organization, a department and business management of an enterprise, etc. get a fully understand of the manual or work system and work flow of the original computer; make clear users' needs; get data flow graph and data dictionary, and based on this to determine the function of the new system and generate requirements specification. What is noteworthy is that the new system must give full consideration to the future possible expansion and change, in stead of designing the database according to the current application.

Concept structure design of the database. On the basis of the requirements specification created in the needs' analysis phase, in accordance with the specific methods to abstract them into data model which is independent to a specific machine. That is the conceptual model. Concept model enables the designer's transfer the attention from complex implementation details, and focus on the organizational structure and processing pattern of the most important information. E-r model is a problem oriented concept model, which is a simple graphical way (e-r chart) to describe the data in the real world. Every entity is the abstract of a real object, and there may be some relationship between every two or more entities.

Logical structure design of the database. Logical design of the database is the first half phrase of the entire database design, including the needed entities and relationships, as well as entity standardization work and so on. In order to set up the final physical system, the concept structure also needs to be further transformed into a data model supported by the DBMS. And then according to the logical design guidelines and the Semantic constraints the data, and standardization theory to adjust and optimize the data model, which leads to form a reasonable logic structure, and get the result of users' mode. Above is the completed task of logic design of a database.

1, the contract table (contract No., lease company, the start date, due date, calculation type, leaseholder, manager of leaseholder, manager No. of leaseholder, project, project amount, guarantor, security manager, security manager No., notes)

2, outbound order list (outbound order No., warehouse, outbound date, status, carrier, car No. , operator, notes)

3, dispatch table (outbound item No., name, type, quantity, stock, unit price, outbound order No., notes)

4, GRN list (such as storage No., warehouse, GRN date, status, carrier, car No., operator, notes)

5, GRN table (storage No., name, type, quantity, stock, unit price, GRN number, notes)

6 , damaged items (damaged item No., name, type, type of maintenance, quantity, unit price, total price)

7, users' table (user table No., name, password, permission, notes)

8 , name list (name list No., name) 
9, type (type No., name, type)

10 equipment table (equipment table No., name, type, specification, unit price, notes)

11, maintenance types' table (maintenance types' table No., name, type, maintenance types, maintenance price)

Physical structure design of the database. Physical structure design of the database is the second half of the database design. To implement a given logical structure to specific environment, the logical data model need to select a specific working environment which provides data storage structure and access method, and this process is physical structure design of the database.

The physical structure depends on the given DBMS and hardware system, so the designer must fully understand the internal characteristics, storage structure and access method of the RDBMS. The physical design of database is usually divided into two steps; first, determine the physical structure of database; second, evaluation of implementation of space efficiency and time efficiency. Then complete the whole physical design on the basis of full understanding of the characteristics of external storage devices. The physical structure design of the database includes; determine the access method of data and determine the data storage structure.

The phase of physical structure design implements is the inner model of database system, and its quality directly determines the performance of the whole system.

\section{System design}

Landing interface: the main function is to realize login of the ordinary users and administrators. Ordinary users and administrators have different permissions which can be conducted by the administrator under backstage data management.

Main interface: the main function provides link for the function; click on the management can link to each implement interface.

Contract management interface: the main function is realized adding contract, modifying, and querying the contract link, and click on the management can link to each implement interface.

Outbound order management interface: the main function is realized adding, modifying, querying outbound order or querying outbound order and adding outbound lists according to the querying conditions.

Outbound items management interface: the main function is realized adding, querying, modifying outbound items or querying outbound order and adding outbound items according to the querying conditions.

Receipt list management interface: the main function is realized adding, querying, modifying outbound items or querying receipt order and adding receipt list according to the querying conditions.

Receipt items management interface: the main function is realized adding, querying, modifying items or querying receipt order and adding receipt items according to the querying conditions.

Damaged management interface: the main function is realized adding and recording the damaged building materials and save in database for settlement.

Settlement management interface: the main function is realized automatic settlement of materials for the lease according to the contract, outbound, inventory and specific algorithm. 


\section{System implementation}

The login interface. After starting the software, a landing interface is displayed, which implements the login of administers based on the user name, password and permission.

The main interface. After login permission, a main interface is displayed, which includes contract management, delivery management, receipt management, damage management and settlement management. Click on the links to get into each interface.

Function module implementation. Contract management interface:

Click on contract management to the new contract and view the contract, in which delivery list and receipt list are created.

Outbound order management interface

Click on outbound management to enter outbound order management interface, which includes create a new outbound item and querying orders based on contract number.

Outbound management interface

Click on outbound items management to enter outbound items management interface, which includes create a new outbound item and querying items.

GRN management interface

Click on GRN management to enter GRN management interface, which includes create a new GRN and querying items.

Warehousing management interface

Click on warehouse management to enter warehouse management interface, which includes create a new receipt and querying items.

Settlement management interface

Click on the settlement management system, and settlement will be realized automatically according to the corresponding contract number.

\section{Conclusions}

This article adopts the way of using case modeling to achieve requirement of the system, and complement the non-functional requirements according to actual situation. In full consideration the extensibility and reusability of the system and development costs, adopts the layered thought to design system overall, and carries out the detailed design on partial function modules, as well as business process in the system. The operation problems are solved according to the actual situation. The function and implementation effects of the system are examined in the actual test.

This paper includes the following several aspects:

(1) The contract management has realized add, modify, query and completed the first step of cooperation between the building leasing company and leaseholders.

(2)Material outbound management realized the construction materials warehouse management of the building leasing company

(3) Overall design of the system according to the layered design method; defined the sequence and interface between the layers; designed functions in the business of the system; realized the most entity class of each system and finally completed the database table design based on designing entity classes. 
(4) receipts management achieved the warehouse management of the building materials leasing company.

(5) The function of implementation and effectiveness of the system are examined by the test.

This paper is based on the management of construction materials and realized modernization management of building supplies leasing company. However, due to the limited time, the system is not completed as the several aspects:

(1) The function of the system is not perfect enough. For example, no design of newsstand management for building material leasing company.

(2) Settlement is not complemented by the month.

In short, with the development of computer and construction technology, the system of building materials leasing management based on JAVA will play an increasingly important role in enterprise management. Lastly, great expectation placed on that the system in the paper is reference for realization and optimization of other software in the construction industry.

\section{Acknowledgements}

This work was financially supported by project of Technology Department of Jiangxi Province [No 20143BBM26048] and the project of Technology Department of Jiangxi Province

\section{References}

[1]O'reilly, Java Servlet Programming,American: Sernni Yey, 2011

[2] Fu,S. Java Web Programming for Beginners Self-study Manual. Beijing: Mechanical Industry Publishing Houses, 2012.10:124-145.

[3] CayS.Horstmann. The Core Technology of Java. The eighth Ed. Beijing: Electronic Industry Press, 2011.7:152-176.

[4] Geng,X. Design Patterns of Java. Beijing: Tsinghua University Press, 2009:38-42.

[5]Chen,T. New Java Program Design Course. Beijing: Tsinghua University Press, 2010.12:44-64.

[6] Bullock. Java based tutorial of Java. Chinese Ed. Beijing: Mechanical Industry Publishing House, 2012.1:89-102.

[8] Olsen. Ajax on java. Southeast University Press, 2011:88-100.

[9] Fan Kaiyuan. 《J2EE-based Enterprise MIS Design and Implementation 》.Energy Procedia.2011, Vol.11, pp.1972-1977 